\title{
Symptom burden and job absenteeism after treatment with additional catheter-directed thrombolysis for deep vein thrombosis
}

This article was published in the following Dove Press journal:

Patient Related Outcome Measures

12 September 2013

Number of times this article has been viewed

\author{
Tone Enden ${ }^{1-3}$ \\ Nils-Einar Kløw ${ }^{2,3}$ \\ Per Morten Sandset ${ }^{1,3}$ \\ 'Department of Hematology, Oslo \\ University Hospital, Oslo, Norway; \\ ${ }^{2}$ Department of Radiology and \\ Nuclear Medicine, Oslo University \\ Hospital, Oslo, Norway; ${ }^{3}$ Institute of \\ Clinical Medicine, University of Oslo, \\ Oslo, Norway
}

Introduction: Additional catheter-directed thrombolysis (CDT) for acute deep vein thrombosis (DVT) reduces long-term postthrombotic syndrome and is likely to represent a cost-effective alternative treatment compared to the standard treatment of anticoagulation and elastic compression stockings. Accelerated thrombus resolution has also been suggested to improve symptoms and patient function in the acute phase. We aimed to investigate whether additional CDT led to fewer symptoms and job absenteeism during the first 6 months after initiation of DVT treatment compared to standard treatment alone.

Methods: The Catheter-directed Venous Thrombolysis (CaVenT) study was a multicenter open label, randomized controlled trial of patients ages 18 years to 75 years with a verified high proximal DVT, $<21$ days of symptoms, and no apparent bleeding risk. Patients were allocated to additional CDT or to standard treatment only. Symptoms were assessed at baseline and at 6 months using items from the generic and disease-specific quality of life questionnaires EQ-5D and VEINES-QOL/Sym, respectively. Individual data on sickness benefits related to venous thromboembolic disease were obtained from the national welfare service.

Results: A total of 90 patients allocated additional CDT and 99 control patients completed longterm follow-up and were included in the analyses. Twenty-four in the CDT arm and 40 controls received sick leave $(P=0.046)$. When considering working patients only (54 in the CDT arm and 72 controls) this difference was no longer statistically significant. Mean duration of job absenteeism was 86.4 days (95\% confidence interval 59.4-113.5) in the CDT arm and 60.1 days (95\% confidence interval 42.3-77.8) in controls $(P=0.072)$. After 6 months, more controls experienced frequent swelling of the leg compared with those allocated to CDT (47 [49.0\%] patients versus 25 [29.4\%] patients, respectively, $[P=0.007])$.

Conclusion: There are limitations to our data, but the findings indicate improved symptom relief and less frequent job absenteeism in patients treated with additional CDT; this expands upon previously established benefits from this treatment.

Keywords: venous thrombosis, patient reported outcomes, thrombolytic therapy, symptom burden, randomized controlled trial, postthrombotic syndrome

\section{Introduction}

Compared to standard treatment with anticoagulation and elastic compression stockings (ECS), additional treatment with catheter-directed thrombolysis (CDT) in patients with an acute high proximal deep vein thrombosis (DVT) results in effective lysis, increases short-term patency, and improves the long-term functional outcome in terms of less postthrombotic syndrome (PTS). ${ }^{1-4}$ PTS symptoms include persistent swelling, pain, and discomfort that is typically most pronounced at the end of the day and is aggravated by standing and walking. Despite a small risk of bleeding, additional CDT is likely to
Correspondence: Tone Enden Department of Radiology, Oslo University Hospital, Postboks 4950 Nydalen, 0424 Oslo, Norway $\mathrm{Tel}+479$ I50 2770

Fax +4722119240

Email tone.enden@medisin.uio.no 
represent a cost-effective treatment alternative and should be considered in patients with no apparent risk of bleeding. ${ }^{5}$ The rationale for introducing thrombolytic treatment for acute DVT was the "open vein hypothesis," which suggested that accelerated resolution of the clot using a thrombolytic agent restores venous function by reducing the two most likely pathophysiologic factors contributing to PTS: persistent lumen obstruction and incompetent venous valves. Based on the same rationale, it has also been suggested that accelerating fibrinolysis may lead to more rapid symptom relief in the acute phase. ${ }^{6}$ To date, this has not been documented in the setting of a randomized controlled trial (RCT). The typical symptoms of acute DVT include unilateral swelling and pain in the leg, but symptoms may be vague and unspecific. The Society of Interventional Radiology's reporting standards for endovascular treatment of DVT recommend repeated assessments during the acute phase using standardized measurement of swelling and validated instruments such as the Visual Analog Scale for pain. ${ }^{6}$ Our study protocol did not include daily assessment of pain, and standardized assessments may be less feasible and valid after the patient is discharged and/or followed in an outpatient treatment setting where factors like activity level, time of day, use of painkillers, and ECS are likely to have an impact on the acute symptoms, which usually subside gradually. Assuming that return to work is a proxy for daily function improvement and symptom relief, we aimed to investigate whether additional CDT led to fewer symptoms and job absenteeism during the first 6 months after initiation of DVT treatment compared to standard treatment alone.

\section{Methods}

The Catheter-directed Venous Thrombolysis (CaVenT) study was an open, multicenter RCT comparing additional CDT with standard treatment alone (anticoagulation and ECS) in patients with a high proximal DVT; the details on the study design and implementation have been reported previously. ${ }^{7}$ Patients 18 years to 75 years of age with an objectively verified DVT above midthigh level with no apparent risk of bleeding, and symptom duration up to 21 days were eligible for inclusion. After obtaining approvals from the Regional Committee for Medical and Health Research Ethics, the Norwegian Medicines Agency, the Data Protectorate, and the Norwegian Labor and Welfare Service, as well as after obtaining informed consent from the study participants, individual data on sickness benefits in terms of paid sick leave were obtained from the Norwegian Labor and Welfare Service. Sick leaves involving any acute or chronic venous thromboembolic condition according to an International Classification of Diseases (ICD) 10th revision or International Classification of Primary Care (ICPC) diagnosis during the first 6 months were included in the analysis. Periods with part-time job absenteeism $(20 \%$ to $99 \%$ of the time) were recalculated as the corresponding number of days of full-time sick leave. Symptom burden was assessed by patients' completion of the quality of life (QOL) instruments EQ-5D (www.euroqol.org) for generic QOL, and the disease-specific VEINES-QOL/Sym at baseline and after 6 months. One VEINES-QOL/Sym item covered work status, whereas the VEINES-Sym subscale covered frequency of symptoms that include pain and swelling during the last 4 weeks (every day, several times a week, about once a week, less than once a week, or never); higher scores indicated a better outcome. ${ }^{8,9}$ From the EQ-5D, we obtained information regarding problems with mobility (no problem, some problem, or confined to bed), usual activities (no problems, some problems, or unable to), and pain/discomfort (none, moderate, extreme). Complete assessment of QOL will be reported elsewhere. PTS was assessed at a 24-month study visit using the Villalta scale, which grades the severity of five patient-rated symptoms (pain, cramps, heaviness, pruritus, paresthesia) and six clinician-rated signs (edema, skin induration, hyperpigmentation, venous ectasia, redness, pain during calf compression) on scores ranging from 0 to 3 ; a summary score of 5 or higher indicates PTS. ${ }^{10,11}$ When comparing dichotomous variables, we used an uncorrected two-sided chi-square test. When comparing continuous variables that were not normally distributed, we used a Mann-Whitney $U$-test. SPSS (version 19; IBM Corporation, Armonk, NY, USA) was used for all analyses.

\section{Results}

Of 209 recruited study participants, 90 patients allocated to additional CDT and 99 control patients completed 24-month follow-up visits. Mean age was 51.5 years (standard deviation: 15.8) and just over one-third were female. Mean duration of symptoms was 6.6 days (standard deviation: 4.6 days) and patients in the CDT arm spent 3 more days in hospital compared with controls (Table 1). Baseline characteristics were fairly equally distributed between the groups, including risk factors for venous thromboembolism and inherited hypercoagulable conditions. ${ }^{3}$

At baseline, 109 (57.7\%) of the study participants reported that they were working. Three controls and two patients in the CDT arm received sick benefits during follow up, although they had reported "I don't work" at baseline. Among the 
Table I Baseline demographic and clinical characteristics

\begin{tabular}{|c|c|c|}
\hline & $\begin{array}{l}\text { Adjunctive catheter- } \\
\text { directed thrombolysis } \\
(n=90)\end{array}$ & $\begin{array}{l}\text { Standard } \\
\text { treatment } \\
\text { only }(n=99)\end{array}$ \\
\hline Age (years) & $53.3(15.7)$ & $50.0(15.8)$ \\
\hline Women & $32(35.6)$ & $38(38.4)$ \\
\hline $\begin{array}{l}\text { Duration of symptoms } \\
\text { (days) }\end{array}$ & $6.4(4.4)$ & $6.8(4.8)$ \\
\hline $\begin{array}{l}\text { Duration of hospital } \\
\text { stay (days) }\end{array}$ & $5.3(4.2)$ & $2.3(2.7)$ \\
\hline $\begin{array}{l}\text { Risk factor(s) for } \\
\text { venous thrombosis }\end{array}$ & $59(65.6)$ & 73 (73.7) \\
\hline $\begin{array}{l}\text { Heterozygous F5 } 6025 \\
\text { polymorphism }\end{array}$ & $23(25.6)$ & $22(22.2)$ \\
\hline $\begin{array}{l}\text { Homozygous F5 } 6025 \\
\text { polymorphism }\end{array}$ & I (I.I) & $4(4.0)$ \\
\hline $\begin{array}{l}\text { Other thrombophilic } \\
\text { factors }\end{array}$ & $15(16.7)$ & $13(13.1)$ \\
\hline
\end{tabular}

Notes: Data on duration are expressed as mean (standard deviation), the remaining as $\mathrm{n}(\%)$.

Abbreviation: $\mathrm{n}$, number.

16 participants with missing work data at baseline, eight had sick leave later. Four remaining participants with missing data were younger than 50 years; for our computation purposes, we assumed that these patients represented working men and women. For the present report, 126 were classified as working; 54 (60.0\%) were allocated to CDT treatment, and $72(72.7 \%)$ comprised the control arm $(P=0.064)$.

On self-completion of the EQ-5D questionnaire at baseline, only one or two patients reported no problems with mobility, usual activities, and pain (data not shown). Baseline symptom burden, as assessed by the mean VEINES-Sym score, was 50.6 (95\% confidence interval [CI] 48.6-52.7) in the CDT arm and 49.6 (95\% CI 47.3-51.9) among controls $(P=0.652)$.

After 6 months of follow-up, the respective mean symptom scores were similar: 51.7 (95\% CI 49.8-53.7) and 48.5 (95\% CI 46.4-50.6). ${ }^{12}$ Approximately $70 \%$ in both treatment arms now reported no problems with mobility or performing usual activities ( $P$-values $>0.30$ ), whereas approximately $50 \%$ still reported pain in general $(P=0.223)$, including five patients in the CDT arm and three controls who reported extreme pain. Nineteen (21.3\%) in the CDT arm and 25 (26.0\%) controls reported aching legs daily or several times a week during the previous 4 weeks $(P=0.454)$, and correspondingly for swelling, this was reported in $25(29.4 \%)$ versus 47 (49.0\%) of patients, $(P=0.007)$.

During the first 6 months after the DVT, 64 patients in total received sick benefits because of thromboembolic disease: $24(26.7 \%)$ patients allocated to CDT versus 40 (40.4\%) controls $(P=0.046)$. When considering only the working proportion, the difference between the treatment groups was no longer statistically significant. There were no differences in proportions who had received sick benefits between men and women (data not shown). Mean duration of the paid sick leaves was 86.4 days (95\% CI 59.4-113.5) in the CDT arm and 60.1 days $(95 \%$ CI $42.3-77.8)$ in controls $(P=0.072)$. Independent of treatment allocation, $35(38.0 \%)$ patients who later developed PTS had received sick benefits during the first 6 months, compared with 29 (29.9\%) of patients who did not $(P=0.237)$. Duration of job absenteeism did not differ among patients who later developed PTS and those without (data not shown).

Mean VEINES-Sym score at baseline and at the 6-month visit did not differ between working patients who received sick benefits in this time period compared to those who had no sick leave; respectively: 51.3 (95\% CI 48.5-54.1) versus 49.5 (95\% CI 47.2-51.9) at baseline $(P=0.177)$ and 49.4 (95\% CI 46.68-52.16) and $50.3(95 \%$ CI 48.61-52.00) at 6 months $(P=0.599)$.

\section{Discussion}

Practically all patients experienced pain, swelling, and problems with mobility and performing their daily activities at the time that they were diagnosed with a high proximal DVT. During the following 6 months, patients treated with additional CDT were less likely to enter sick leave compared with control patients. When excluding study participants who reported not working, this difference was no longer statistically significant. Mean duration of the paid sick leaves did not differ between the treatment groups. Symptom burden improved during the 6-month follow-up period, and the majority of patients did not experience problems with mobility or usual activities any longer. However, a minority of patients in both groups still experienced daily or frequent occurrence of aching legs. Finally, nearly half of the controls reported persistent daily or frequent swelling after 6 months, and this was nearly twice as frequent as that in the CDT arm. This result corresponded well with our previous finding of less PTS in patients who were allocated additional CDT. ${ }^{3}$ The long-term clinical benefit in terms of reduction in PTS should still be considered the more important outcome measure in trials on venous thrombolysis; however, the present report indicates a supplemental short term beneficial effect that is likely to be clinically relevant as well.

The VEINES-QOL/Sym instrument was developed for chronic venous disease, and the symptom component asks about the frequency of symptoms experienced during the last 4 weeks. ${ }^{8}$ This question was confusing to patients at 
baseline (personal observation) and this is likely to reflect that their mean duration of symptoms was only 6.6 days and no more than 21 days. Hence, we consider the VEINES-Sym subscale less appropriate for self-reporting of acute DVT symptoms than the EQ-5D, which asks about "your own health state today" (www.euroqol.org). However, reporting of pain in EQ-5D refers to pain in general, not to leg pain only. Finally, in addition to the symptom subscale and individual questionnaire items, employing a tool such as the Visual Analog Scale for standardized pain assessment could have easily been added to the study setup and might have added valuable information. ${ }^{6}$ The ongoing American ATTRACT (NCT00790335) and Dutch CAVA (NCT00970619) trials are likely to add to the documentation of short-term intermediate outcomes after venous thrombolysis, including symptom relief (www.clinicaltrials.gov).

The consequences of reducing job absenteeism are desirable for the patient, the employer, and the social welfare system; this applies especially to chronic conditions. In the Norwegian setting, with complete coverage of up to 1 year sick leave, the patients did not suffer economically during the study period, but negative effects of long-term job absenteeism because of health problems, including impaired sleep and psychological well-being, have been identified. ${ }^{13}$ Our findings were divergent in demonstrating a benefit from CDT treatment in terms of reducing sick leave. We have previously shown that additional CDT is likely to be a cost-effective treatment strategy; ${ }^{5}$ however, job absenteeism was not included in that economic evaluation, which took a third payer perspective and did not include indirect costs such as productivity losses. Finally, according to economic theory, costs related to sick benefits are considered money transfers and not foregone resources, and are not included in cost-effectiveness analyses. ${ }^{14}$

Reports on use of sick leave after DVT are limited. In a Swedish study on DVT-related costs, only $9 \%$ to $18 \%$ of patients received sick leave during the first 3 months. ${ }^{15}$ This likely reflects the less extensive thrombosis noted in that study population compared with that of the CaVenT study participants. In a case-control study of the long-term consequences of pregnancy-related DVT, patients with PTS reported more frequent sick leave during the previous year than did those without PTS. ${ }^{16}$ Our findings did not support this, but our study had a shorter follow-up period, and this may also reflect differences in the two populations. In a prospective Canadian cohort study, greater symptom burden 1 month after a DVT diagnosis was an independent predictor of long-term postthrombotic severity. ${ }^{17}$ Our findings indicating improved symptom severity and fewer sick leaves in the CDT arm during the first 6 months combined with reduced PTS (previously reported) ${ }^{3}$ are likely to reflect this association between early symptom burden and long-term outcomes. However, in addition to possibly low statistical power, this interpretation is limited by the lack of study visits and longitudinal follow-up between baseline and 6 months. Another limitation is the lack of validated data on baseline work status. Job absenteeism is registered in the Norwegian Labor and Welfare Service only after the patient is discharged from the hospital, and personal declaration days (ie, 1 day to 3 days) were not included because they are not registered with a particular diagnosis. However, this is unlikely to have an impact on our analysis, as all patients had their DVT diagnosis verified in a hospital setting; all were discharged with arrangements for follow-up on their anticoagulation and international normalized ratio monitoring, and when sick leave was indicated, it would be certified by the physician. The strengths of our report include the setting within an RCT that assures internal validation and avoids confounding. Finally, all sickness benefits were obtained individually as registered at the Norwegian Labor and Welfare Service, avoiding any recall bias on the duration of sickness absence. ${ }^{18}$

\section{Conclusion}

Patients allocated additional CDT were less likely to receive sickness benefits during the first 6 months after a high proximal DVT compared with patients in the standard treatment arm; however, there was no difference in the duration of sick leave between the treatment groups. The difference was supported by a higher persistent symptom burden in terms of swelling in control patients. These findings expand upon previously shown benefits from additional CDT.

\section{Disclosure}

The authors report no conflicts of interest in this work.

\section{References}

1. Haig Y, Enden T, Slagsvold CE, Sandvik L, Sandset PM, Kløw NE. Determinants of early and long-term efficacy of catheter-directed thrombolysis in proximal deep vein thrombosis. J Vasc Interv Radiol. 2013;24(1):17-24.

2. Enden T, Kløw NE, Sandvik L, et al; for CaVenT study group. Catheterdirected thrombolysis vs anticoagulant therapy alone in deep vein thrombosis: results of an open randomized, controlled trial reporting on short-term patency. J Thromb Haemost. 2009;7(8):1268-1275.

3. Enden T, Haig Y, Kløw NE, et al; for CaVenT Study Group. Long-term outcome after additional catheter-directed thrombolysis versus standard treatment for acute iliofemoral deep vein thrombosis (the CaVenT study): a randomised controlled trial. Lancet. 2012;379(9810):31-38. 
4. Kearon C, Akl EA, Comerota AJ, et al; for American College of Chest Physicians. Antithrombotic therapy for VTE disease: Antithrombotic Therapy and Prevention of Thrombosis, 9th ed: American College of Chest Physicians Evidence-Based Clinical Practice Guidelines. Chest. 2012;141(Suppl 2):e419S-e494S.

5. Enden T, Resch S, White C, Wik HS, Kløw NE, Sandset PM. Cost-effectiveness of additional catheter-directed thrombolysis for deep vein thrombosis. J Thromb Haemost. Epub March 2, 2013.

6. Vedantham S, Grassi CJ, Ferral H, et al; for Technology Assessment Committee of the Society of Interventional Radiology. Reporting standards for endovascular treatment of lower extremity deep vein thrombosis. J Vasc Interv Radiol. 2009;20(Suppl 7): S391-S408.

7. Enden T, Sandvik L, Kløw NE, et al. Catheter-directed venous thrombolysis in acute iliofemoral vein thrombosis - the CaVenT study: rationale and design of a multicenter, randomized, controlled, clinical trial (NCT00251771). Am Heart J. 2007;154(5):808-814.

8. Lamping DL, Schroter S, Kurz X, Kahn SR, Abenhaim L. Evaluation of outcomes in chronic venous disorders of the leg: development of a scientifically rigorous, patient-reported measure of symptoms and quality of life. J Vasc Surg. 2003;37(2):410-419.

9. Enden T, Garratt AM, Kløw NE, Sandset PM. Assessing burden of illness following acute deep vein thrombosis: data quality, reliability and validity of the Norwegian version of VEINES-QOL/ Sym, a disease-specific questionnaire. Scand J Caring Sci. 2009;(2): 369-374.

10. Villalta S, Bagatella P, Piccioli A, Lensing AW, Prins MH, Prandoni P. Assessment of validity and reproducibility of a clinical scale for the postthrombotic syndrome. Haemostasis. 1994;24(Suppl 1):158a.
11. Kahn SR, Partsch H, Vedantham S, Prandoni P, Kearon C; for Subcommittee on Control of Anticoagulation of the Scientific and Standardization Committee of the International Society on Thrombosis and Haemostasis. Definition of post-thrombotic syndrome of the leg for use in clinical investigations: a recommendation for standardization. J Thromb Haemost. 2009;7(5):879-883.

12. Enden T, Wik HS, Kvam AK, et al. Health-related quality of life after catheter-directed thrombolysis for deep vein thrombosis: secondary outcomes of the randomised, non-blinded, parallel-group CaVenT study. BMJ Open. 2013;3:e002984.

13. Floderus B, Göransson S, Alexanderson K, Aronsson G. Self-estimated life situation in patients on long-term sick leave. J Rehabil Med. 2005;37(5):291-299.

14. Nord E. Health economics - short introduction to cost-benefit analyses. Tidsskr Nor Laegeforen. 2002;122(28):2719-2722. Norwegian.

15. Bäckman K, Carlsson P, Kentson M, Hansen S, Engquist L, Hallert C. Deep venous thrombosis: a new task for primary health care. A randomised economic study of outpatient and inpatient treatment. Scand J Prim Health Care. 2004;22(1):44-49.

16. Wik HS, Jacobsen AF, Sandvik L, Sandset PM. Long-term impact of pregnancy-related venous thrombosis on quality-of-life, general health and functioning: results of a cross-sectional, case-control study. $B M J$ Open. 2012;2(6):e002048

17. Kahn SR, Shrier I, Julian JA, et al. Determinants and time course of the postthrombotic syndrome after acute deep venous thrombosis. Ann Intern Med. 2008;149(10):698-707.

18. Grovle L, Haugen AJ, Keller A, Natvig B, Brox JI, Grotle M. Poor agreement found between self-report and a public registry on duration of sickness absence. J Clin Epidemiol. 2012;65(2):212-218.
Patient Related Outcome Measures

\section{Publish your work in this journal}

Patient Related Outcome Measures is an international, peer-reviewed, open access journal focusing on treatment outcomes specifically relevant to patients. All aspects of patient care are addressed within the journal and practitioners from all disciplines are invited to submit their work as well as healthcare researchers and patient support groups.

\section{Dovepress}

The manuscript management system is completely online and includes a very quick and fair peer-review system. Visit http://www.dovepress. $\mathrm{com} /$ testimonials.php to read real quotes from published authors. 